\title{
Comparison of COPD Assessment Test and Clinical COPD Questionnaire to predict the risk of exacerbation
}

This article was published in the following Dove Press journal: International Journal of COPD

Yong Suk Jo'

Ho II Yoon ${ }^{2}$

Deog Kyeom Kim ${ }^{3}$

Chul-Gyu Yoo'

Chang-Hoon Lee'

'Division of Pulmonary and Critical Care Medicine, Department of Internal Medicine, Seoul National University Hospital, Seoul, ${ }^{2}$ Division of Pulmonary and Critical Care Medicine, Department of Internal Medicine, Seoul National University Bundang Hospital, Seongnam, Gyeonggi, ${ }^{3}$ Division of Pulmonary and Critical Care Medicine, Department of Internal Medicine, Seoul Metropolitan Government-Seoul National University Boramae Medical Center, Seoul, Republic of Korea
Correspondence: Chang-Hoon Lee Division of Pulmonary and Critical Care Medicine, Department of Internal Medicine, Seoul National University Hospital, I0I Daehak-Ro Jongno-Gu, Seoul 03080, Republic of Korea

Tel +82 220724743

Fax +82 27629662

Email kauri670@empal.com
Background and objective: Guidelines recommend the use of simple but comprehensive tools such as COPD Assessment Test (CAT) and Clinical COPD Questionnaire (CCQ) to assess health status in COPD patients. We aimed to compare the ability of CAT and CCQ to predict exacerbation in COPD patients.

Methods: We organized a multicenter prospective cohort study that included COPD patients. The relationships between CAT, CCQ, and other clinical measurements were analyzed by correlation analysis, and the impact of CAT and CCQ scores on exacerbation was analyzed by logistic regression analyses and receiver operating characteristic curve.

Results: Among 121 COPD patients, CAT and CCQ score correlated with other symptom measures, lung function and exercise capacity as well. Compared with patients who did not experience exacerbation, those who experienced exacerbation $(n=45 ; 38.2 \%)$ exhibited more severe airflow limitation, were more likely to have a history of exacerbation in the year prior to enrollment, and demonstrated higher CAT scores. CCQ scores were not significantly associated with exacerbations. A CAT score of $\geq 15$ was an independent risk factor for exacerbation (adjusted odds ratio [aOR], 2.40; 95\% CI, 1.03-6.50; $P=0.04$ ). Furthermore, CAT scores of $\geq 15$ demonstrated an increased predictive ability for exacerbation compared with currently accepted guidelines for the use of CAT $(\geq 10)$ and CCQ $(\geq 1)$ in the assessment of COPD patients (area under the curve for $\mathrm{CAT} \geq 15, \mathrm{CAT} \geq 10$, and $\mathrm{CCQ} \geq 1$ was $0.61 \pm 0.04,0.53 \pm 0.03$, and $0.50 \pm 0.03$, respectively; $P=0.03$ ).

Conclusion: A CAT score of $\geq 15$ indicates increased risk of exacerbation in COPD patients, whereas there is no evidence for increased risk based on CCQ score.

Keywords: COPD, exacerbation, questionnaire

\section{Introduction}

COPD is a disease characterized by persistent respiratory symptoms and airflow limitation. The level of airflow limitation, represented by forced expiratory volume in 1 second $\left(\mathrm{FEV}_{1}\right)$, has been regarded as an important index in the prediction of clinical outcomes; ${ }^{1-3}$ however, correlations between $\mathrm{FEV}_{1}$ and either symptoms or impairment of a patient's health status have been noted as weak. ${ }^{4,5}$ In fact, the goals of COPD assessment are to determine not only the severity of airflow limitation but also the patients' disease-specific self-perceived health status and the risk of future adverse events, including exacerbations; an additional goal is to guide future therapeutic approaches. ${ }^{6}$ Exacerbation leads to an increased frequency of emergency department visits and subsequent hospitalization to achieve symptom relief; furthermore, it results in increased morbidity, mortality, and medical cost, making exacerbation an important 
outcome measure in COPD. ${ }^{7-9}$ Current clinical guidelines recommend the evaluation of future exacerbation risk based on previous exacerbation history and severity of dyspnea or poor quality of life status. ${ }^{6}$

The modified Medical Research Council (mMRC) assessment is widely used, and an mMRC score of $\geq 2$ is still referenced as a threshold to discriminate "more breathlessness" from "less breathlessness." Although the severity of dyspnea is a proven predictor of patient outcomes, including exacerbation and mortality in patients with COPD, ${ }^{10}$ a comprehensive assessment of the patients' perceived health status should be used in addition to the mMRC assessment, rather than simple measurement of breathlessness alone.

To estimate the severity of disease-specific symptoms and their impact on quality of life, multiple well-validated and accepted assessment tools have been created. The most notable of these is the St George's Respiratory Questionnaire (SGRQ). The SGRQ is the most widely accepted comprehensive symptom measure, but its complexity and the difficulty associated with its calculations can make it impractical to use; therefore, the COPD Assessment Test (CAT) and Clinical COPD Questionnaire (CCQ) are used as alternatives to the SGRQ. ${ }^{6}$ The Global Initiative for Chronic Obstructive Lung Disease (GOLD) guidelines suggest a CAT score of 10 to use as a threshold for beginning regular COPD treatment (more symptomatic), ${ }^{6}$ but in the case of CCQ, an adequate threshold is not yet determined. In addition, recent studies suggest that the threshold of CAT for regular COPD treatment needs to be revised upward. ${ }^{11,12}$

It has been reported that symptoms measured by mMRC, ${ }^{13}$ SGRQ, ${ }^{14,15} \mathrm{CAT},{ }^{10,16}$ and $\mathrm{CCQ}^{10,17}$ are important predictors of COPD mortality and exacerbation. However, there are minimal data regarding which questionnaire (CAT or CCQ) has better ability to predict exacerbation in COPD patients. Therefore, in the current study, we aimed to compare the usefulness of CAT and CCQ scores for the prediction of exacerbation and find the appropriate value for discriminating patients with COPD who are at risk for future exacerbation in a prospective observational cohort of COPD.

\section{Patients and methods}

\section{Study participants and design}

The Seoul National University Airway Registry is an active ongoing multicenter, prospective observational cohort that enrolls patients with chronic airway disease. The patients included in this study were enrolled between April 2013 and November 2016 at Seoul National University Hospital (a tertiary care hospital) and between March 2014 and November
2016 at both Seoul Metropolitan Government-Seoul National University Boramae Medical Center and Seoul National University Bundang Hospital (ClinicalTrials.gov identifier: NCT02527486). Patients aged $\geq 40$ years with post-bronchodilator $\mathrm{FEV}_{1}$ /forced vital capacity $(\mathrm{FVC})<0.7$, who were current or former smokers of at least 10 pack-years, were included in the study. We excluded patients who were diagnosed with other chronic respiratory diseases, including bronchial asthma.

Subjects with COPD were currently undergoing regular follow-up visits, and assessments included in the current study were made at baseline and 1-year visits. Assessments of the current study included demographic and anthropometric data (height, weight, and body mass index), smoking history and severity of dyspnea (mMRC, scale 0-4), health-related quality-of-life questionnaires (SGRQ, scale 0-100; CAT, scale 0-40; and CCQ, scale 0-6), exercise capacity (6-minute walk distance [6MWD]), pulmonary function measurements, and treatment.

All patients signed an informed consent form to participate in this observational cohort. This study was approved by the institutional review board of Seoul National University Hospital.

\section{Clinical measurements}

Pulmonary function tests were performed by standardized equipment, and lung volume was measured following the American Thoracic Society ${ }^{18} /$ European Respiratory Society (ERS) guidelines. ${ }^{19}$ Pulmonary function tests were repeated at least three times to verify reproducibility and validity, and assessments of the results were conducted using computer programs and reviewed by highly qualified physicians. The 6MWD test was performed according to the standardized guidelines; ${ }^{20}$ severity of dyspnea was measured with the mMRC scale; and the CAT, CCQ, and SGRQ questionnaires were self-reported by each patient with the supervision of a trained qualified interviewer.

\section{Exacerbation}

Exacerbation was defined as an event related to the worsening of respiratory symptoms, which leads to use of antibiotics, steroids, or both, or a visit to the emergency room or hospitalization. The date and frequency of exacerbation was measured based on patients' self-report at every 3-month visit. To assess predictability of each health-related questionnaire on future exacerbation, we only analyzed patients who followed up at least a year. For this reason, among 246 patients with COPD, 121 patients were included in the final analysis. 


\section{CAT}

The CAT consists of eight items that reflect the most bothersome health-related symptoms and activity limitations of COPD: cough, phlegm, chest tightness, breathlessness on going uphills or stairs, any activity limitation at home, confidence leaving home, sleep, and energy. The scale of each item ranged from 0 to 5 point, and in total ranged from 0 to 40 , with higher scores indicating poor perception of disease-related health status. The minimum clinically important difference (MCID) value is 2 points. ${ }^{21-23}$ The GOLD suggests a CAT score of $\geq 10$ as an equivalent symptom score to an $\mathrm{SGRQ} \geq 25$, which is regarded as the threshold for considering regular treatment for COPD. ${ }^{6}$ The Korean version of CAT had been validated, ${ }^{24}$ and the previous study has reported a CAT score of $\geq 15$ to reliably predict future exacerbations. ${ }^{11}$

\section{CCQ}

The CCQ is composed of 10 items distributed in three domains (symptom, functional, and mental state) assessed by a 7-point scale from 0 to 6 , which indicates the best (asymptomatic and no limitation) and worst conditions (extremely symptomatic and limited). ${ }^{25}$ The total score of CCQ is calculated by summing the scores of questions applied and dividing it by the number of questions. We applied the previously validated Korean version of the CCQ, ${ }^{26}$ which is free for use in noncommercial activities. ${ }^{27}$ The GOLD suggests that a CCQ score range of 1.0-1.5 is equivalent to an SGRQ score of 25, and recent studies suggest that the MCID for the CCQ is $\sim 0.4 .^{28}$

\section{Statistical analysis}

Quantitative variables are expressed as mean \pm SD; qualitative variables are expressed as absolute number and percentages unless stated otherwise. Pearson's Chi-square test for categorical variables and Student's $t$-test for continuous variables were used to compare baseline characteristics. Pearson correlation tests were applied to characterize the relationships of CAT and CCQ with other clinical measurements including SGRQ, $\mathrm{FEV}_{1}$, and 6MWD.

The risks of exacerbation during the 1-year follow-up period were investigated. Univariate and multivariable logistic regression analyses adjusted by covariates were applied to identify the risk factors for exacerbation. The area under the receiver operating characteristic (AUROC) curve was applied to compare the prediction ability for exacerbation risk according to CAT and CCQ with different thresholds. We applied 10 and 15 as thresholds for CAT, and used 1.0 and 1.4 as thresholds for CCQ.
All analyses were two sided and set at a significance level of $0.05 ; P<0.05$ was considered statistically significant. All analyses were carried out using Stata version 14.2 (StataCorp LP, College Station, TX, USA).

\section{Results \\ Participants and exacerbation during follow-up}

A total of 246 patients with COPD were assessed at baseline, of whom 121 patients returned for at least 1 year and had CCQ or CAT results that were available for analysis (Figure 1). During the 1-year follow-up, 45 patients (38.2\%) experienced exacerbation. Participants who experienced exacerbation during 1 year had a lower $\mathrm{FEV}_{1}$ and had undergone more exacerbation events in the past year before enrollment ( $1.9 \pm 3.2$ vs $0.5 \pm 1.3$ events/year; $P<0.01$ ), compared with those who did not experience exacerbation. Those who experienced exacerbation had a significantly higher CAT score than those who did not (19.5 \pm 8.4 vs $16.2 \pm 7.3 ; P=0.02)$; however, there were no significant differences in mMRC grade, SGRQ, or CCQ between the two groups (Table 1).

More patients who experienced exacerbation were prescribed combination of inhaled corticosteroid (ICS)/longacting $\beta_{2}$ agonist (LABA) inhalers than those who did not experience exacerbation (22 out of 45 [48.9\%] vs 33 out of $76[43.4 \%]$ patients, $P=0.56)$.

\section{Relationship between CAT, CCQ, and other measurements}

Figure 2 shows a correlation of questionnaires (CAT for Figure 2A-C and CCQ for Figure 2D-F, respectively) with other symptom assessment tools ( $\mathrm{SGRQ}$ ), $\mathrm{FEV}_{1}$, and exercise capacity (6MWD). Both CAT and CCQ showed a strong positive correlation with SGRQ ( $r=0.71$ and 0.74 , respectively).

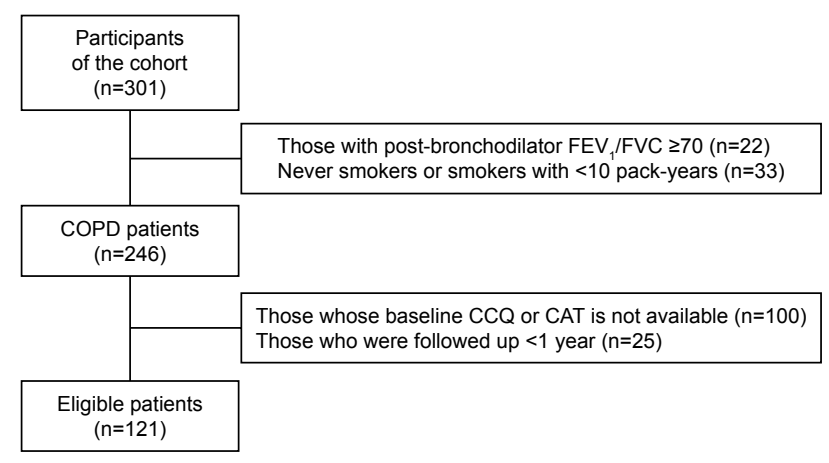

Figure I Flow diagram of the included study participants.

Abbreviations: CAT, COPD Assessment Test; CCQ, Clinical COPD Questionnaire; $\mathrm{FEV}_{1}$, forced expiratory volume in I second; FVC, forced vital capacity. 
Table I Baseline characteristics of patients with and without exacerbation

\begin{tabular}{|c|c|c|c|}
\hline Characteristics & $\begin{array}{l}\text { Patients } \\
\text { with an } \\
\text { exacerbation } \\
(n=45)\end{array}$ & $\begin{array}{l}\text { Patients } \\
\text { without an } \\
\text { exacerbation } \\
(n=76)\end{array}$ & $P$-value \\
\hline Age, years & $70.5 \pm 7.1$ & $71.9 \pm 7.9$ & 0.33 \\
\hline Male & $44(97.8)$ & $74(97.4)$ & 0.89 \\
\hline BMI, kg/m² & $23.6 \pm 3.5$ & $22.6 \pm 3.0$ & 0.13 \\
\hline \multicolumn{4}{|l|}{ Smoking status } \\
\hline Former smoker & $31(72.1)$ & $55(73.3)$ & 0.88 \\
\hline Current smoker & $12(27.9)$ & $20(26.7)$ & \\
\hline Pack-years & $51.4 \pm 30.3$ & $45.9 \pm 22.2$ & 0.25 \\
\hline \multicolumn{4}{|c|}{ History of exacerbation in the past year } \\
\hline Exacerbations (yes, \%) & $26(57.8)$ & $22(28.9)$ & $<0.01$ \\
\hline $\begin{array}{l}\text { Frequency of } \\
\text { exacerbation (no/year) }\end{array}$ & $1.9 \pm 3.2$ & $0.5 \pm 1.3$ & $<0.01$ \\
\hline \multicolumn{4}{|l|}{ Lung function } \\
\hline $\mathrm{FEV}_{1}, \mathrm{~L}$ & $1.5 \pm 0.5$ & $1.7 \pm 0.5$ & 0.06 \\
\hline $\mathrm{FEV}_{1}, \%$ & $60.6 \pm 18.1$ & $68.3 \pm 19.3$ & 0.03 \\
\hline FVC, L & $3.5 \pm 0.8$ & $3.5 \pm 0.8$ & 0.64 \\
\hline FVC, \% & $94.8 \pm 20.8$ & $95.2 \pm 18.2$ & 0.90 \\
\hline $\mathrm{FEV}_{1} / \mathrm{FVC}$ & $43.0 \pm 11.2$ & $48.7 \pm 10.3$ & $<0.01$ \\
\hline \multicolumn{4}{|l|}{ GOLD grade } \\
\hline I $\left(\mathrm{FEV}_{1}>80 \%\right.$ predicted $)$ & $4(8.9)$ & $19(25.0)$ & 0.03 \\
\hline $\begin{array}{l}2(\mathrm{FEV}, 50 \%-79 \% \\
\text { predicted) }\end{array}$ & $28(62.2)$ & $43(56.6)$ & \\
\hline $\begin{array}{l}3(\mathrm{FEV}, 30 \%-49 \% \\
\text { predicted) }\end{array}$ & $10(22.2)$ & $14(18.4)$ & \\
\hline $4\left(\mathrm{FEV}_{1}<30 \%\right.$ predicted $)$ & $3(6.7)$ & $0(0)$ & \\
\hline SGRQ score & $40.3 \pm 19.5$ & $34.7 \pm 17.7$ & 0.11 \\
\hline mMRC grade & $1.4 \pm 0.8$ & $1.4 \pm 0.9$ & 0.81 \\
\hline 6MWD, m & $443.0 \pm 109.7$ & $424.5 \pm 124.3$ & 0.43 \\
\hline CAT score & $19.5 \pm 8.4$ & $16.2 \pm 7.3$ & 0.02 \\
\hline CCQ score & $2.1 \pm 1.0$ & $1.9 \pm 0.9$ & 0.28 \\
\hline
\end{tabular}

Note: Data are presented as number (\%) or mean \pm standard deviation. Abbreviations: BMI, body mass index; CAT, COPD Assessment Test; CCQ, Clinical COPD Questionnaire; FEV, forced expiratory volume in I second; FVC, forced vital capacity; GOLD, Global Initiative for Chronic Obstructive Lung Disease; mMRC, modified Medical Research Council; 6MWD, 6-minute walk distance; SGRQ, St George's Respiratory Questionnaire.

However, CAT was weakly and CCQ was moderately negatively correlated with $\mathrm{FEV}_{1}$ and 6MWD. CAT and CCQ were strongly positively correlated with each other $(r=0.70, P<0.01)$.

\section{CAT and CCQ as predictors of exacerbation risk}

A CAT score of $\geq 15$, a prior history of exacerbation, and a low $\mathrm{FEV}_{1} \%$ were significantly associated with an increased risk of exacerbation on univariate analysis. Even after adjusting for covariates including age, sex, smoking status, $\mathrm{FEV}_{1} \%$, and treatment with ICS/LABA, a CAT score of $\geq 15$ was an independent predictor for increased risk of exacerbation (multivariate model 1: adjusted odds ratio [aOR], 2.58;
95\% CI, 1.03-6.50; $P=0.04)$. However, the impact of CAT was attenuated when the prior history of exacerbation was added to the multivariate model (multivariate model 2: aOR, 2.40; 95\% CI, $0.92-6.25 ; P=0.07)$. The other thresholds of CAT and CCQ did not have a significant association with the risk of exacerbation (Table 2).

Figure 3 shows the predictive power of CAT and CCQ scores for COPD exacerbation. A CAT score of $\geq 10$ and a CCQ score of $\geq 1$ had similar AUROC $(0.53 \pm 0.03$ vs $0.50 \pm 0.03 ; P=0.40)$. However, CAT threshold of 15 provided better prediction than CAT threshold of 10 and CCQ threshold of 1 (AUROC, $0.61 \pm 0.04$ vs $0.53 \pm 0.03$ vs $0.50 \pm 0.03 ; P=0.03)$.

\section{Discussion}

In the current prospective observational study, we made several important observations. To our knowledge, this is the first study comparing the ability of CAT and CCQ assessments to predict exacerbation, especially in Asian COPD patients. In addition, we have shown that the CAT has a higher capacity to predict exacerbation than CCQ, and that a CAT threshold of 15 reliably predicts exacerbation.

The SGRQ is the most widely accepted comprehensive assessment tool of health status in chronic respiratory disease patients, composed of 50 items and requiring complicated scoring spreadsheets that make it difficult to use in practice. ${ }^{21,25,29,30}$ In contrast, the CAT and CCQ are simple, easy to use, and short questionnaires that can be completed in 2 minutes by most patients. CAT and CCQ have both been translated into several languages for noncommercial use and are free of charge for both clinicians and patients. ${ }^{21,25}$ Both questionnaires have been well correlated with the SGRQ, ${ }^{21,31}$ the mMRC dyspnea scale, ${ }^{16}$ and each other ${ }^{32-35}$ The average time for questionnaire completion is slightly shorter for the CAT than for the CCQ, ${ }^{32}$ but the CCQ is preferred by a slightly higher number of patients and requires less assistance to complete. ${ }^{32,33}$

The updated GOLD guidelines recommend the use of CAT as a symptom assessment tool for COPD patients, but the CCQ is described as an alternative. On the other hand, the International Primary Care Respiratory Group performed an analysis of nine assessment instruments as "COPD wellness tools" and ranked the CCQ as the best and the CAT as the second best for use in clinical practice. ${ }^{36}$ Aside from practical usefulness, these two assessment tools have been rarely validated in Asia; the CCQ is especially not well validated.

These questionnaires are suitable to evaluate health status in COPD patients. ${ }^{6}$ Ideally, the assessment of a patient's 
A

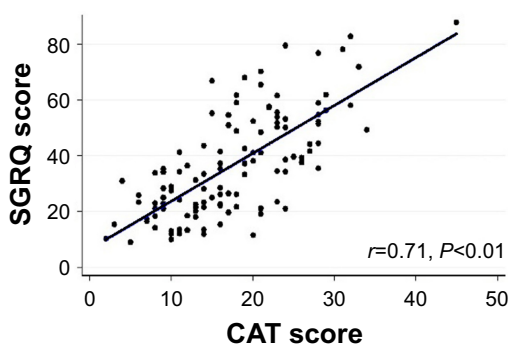

D

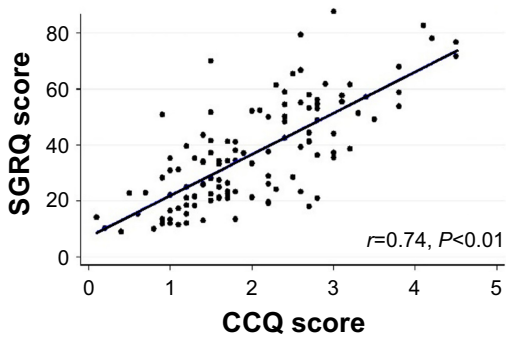

- SGRQ score $\longrightarrow$ Fitted values
B

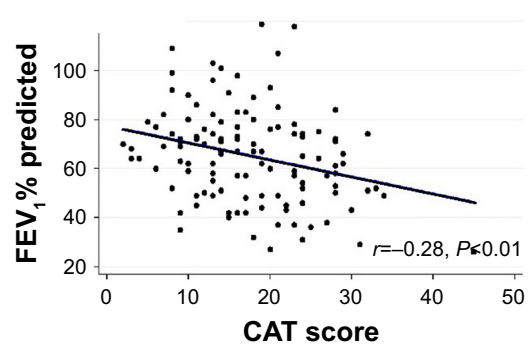

E

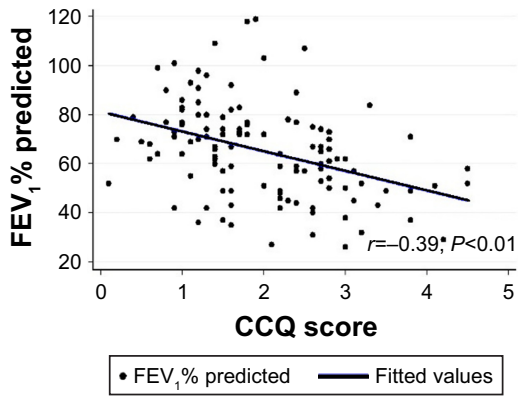

C

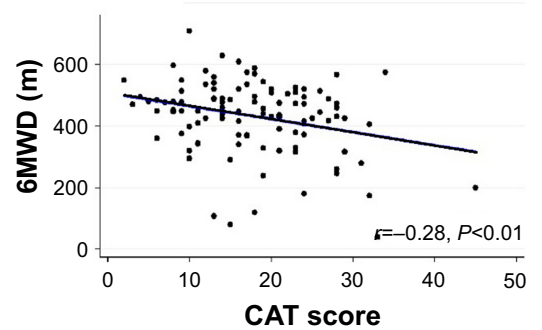

$\mathbf{F}$

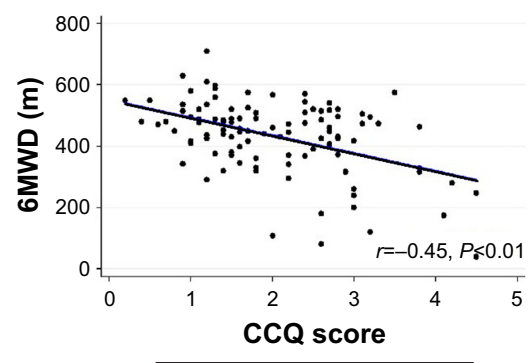

-6MWD, $\mathrm{m}$ - Fitted values

Figure 2 Correlation of CAT and CCQ scores with SGRQ (A and D), FEV \% predicted (B and E), and 6MWD (C and F).

Abbreviations: CAT, COPD Assessment Test; CCQ, Clinical COPD Questionnaire; FEV , forced expiratory volume in I second; 6MWD, 6-minute walk distance; SGRQ, St George's Respiratory Questionnaire.

health status will facilitate the prediction of future risk. Previous studies have indicated that health status, as assessed by CAT and CCQ methods, has the capacity to predict COPD patients at higher risk of exacerbation events. ${ }^{10,37}$ However, there have been no studies comparing the ability of these assessment tools to predict exacerbation events.
In the current study, we found that, compared with the CCQ, the CAT is better able to predict future exacerbation events. The CAT is a one-directional questionnaire, whereas the CCQ is composed of three domains and is more heavily influenced by emotional states, such as anxiety and depression. ${ }^{38}$ Although the CAT and CCQ are both

Table 2 Predictors of exacerbation during I-year follow-up period

\begin{tabular}{|c|c|c|c|c|c|c|c|c|c|}
\hline \multirow[t]{2}{*}{ Variables } & \multicolumn{3}{|c|}{ Univariate analysis } & \multicolumn{3}{|c|}{ Multivariate model la } & \multicolumn{3}{|c|}{ Multivariate model $2^{\mathrm{b}}$} \\
\hline & OR & $95 \% \mathrm{Cl}$ & $P$-value & aOR & $95 \% \mathrm{Cl}$ & $P$-value & aOR & $95 \% \mathrm{Cl}$ & $P$-value \\
\hline Age & 0.98 & $0.93-1.02$ & 0.33 & 0.98 & $0.92-1.03$ & 0.39 & 1.00 & $0.95-1.07$ & 0.85 \\
\hline Sex (male) & 1.19 & $0.10-13.50$ & 0.89 & 0.41 & $0.02-8.77$ & 0.57 & 1.05 & $0.05-23.83$ & 0.97 \\
\hline $\begin{array}{l}\text { History of exacerbation } \\
\text { in the past year }\end{array}$ & 3.36 & I.55-7.27 & $<0.01$ & & & & 3.36 & $1.38-8.19$ & 0.01 \\
\hline Smoking packs/year & I.0I & $0.99-1.02$ & 0.25 & I.0I & $0.99-1.02$ & 0.45 & 1.00 & $0.99-1.02$ & 0.70 \\
\hline $\mathrm{FEV}_{1}(\%)$ & 0.98 & $0.96-1.00$ & 0.03 & 0.98 & $0.96-1.00$ & 0.14 & 0.98 & $0.96-1.01$ & 0.18 \\
\hline FVC (\%) & 1.00 & $0.98-1.02$ & 0.90 & & & & & & \\
\hline $\mathrm{FEV}_{\mathrm{l}} / \mathrm{FVC}$ & 0.95 & $0.92-0.99$ & 0.01 & & & & & & \\
\hline $\mathrm{mMRC} \geq 2$ & 0.92 & $0.42-1.99$ & 0.83 & & & & & & \\
\hline SGRQ $\geq 25$ & $\mathrm{I} .48$ & $0.66-3.29$ & 0.34 & & & & & & \\
\hline $\mathrm{CAT} \geq 10$ & 1.60 & $0.57-4.47$ & 0.37 & & & & & & \\
\hline $\mathrm{CAT} \geq 15$ & 2.61 & I. $17-5.80$ & 0.02 & 2.58 & $1.03-6.50$ & 0.04 & 2.40 & $0.92-6.25$ & 0.07 \\
\hline $\mathrm{CCQ} \geq \mathrm{I}$ & 1.07 & $0.34-3.43$ & 0.90 & & & & & & \\
\hline $\mathrm{CCQ} \geq \mathrm{I} .4$ & 0.84 & $0.38-1.82$ & 0.65 & & & & & & \\
\hline Use of LAMA & 1.33 & $0.62-2.82$ & 0.46 & & & & & & \\
\hline Use of ICS/LABA & 1.25 & $0.59-2.61$ & 0.56 & 0.98 & $0.42-2.26$ & 0.96 & 1.03 & $0.43-2.45$ & 0.95 \\
\hline
\end{tabular}

Notes: aMultivariate analysis was performed by adjusting for age, sex, baseline FEV,\%, CAT $\geq 15$, smoking packs/year, and use of ICS/LABA. ${ }^{b}$ Multivariate analysis was performed by adjusting for age, sex, history of exacerbation in the past year, baseline FEV \%, CAT $\geq I 5$, smoking packs/year, and use of ICS/LABA.

Abbreviations: aOR, adjusted OR; CAT, COPD Assessment Test; CCQ, Clinical COPD Questionnaire; FEV , forced expiratory volume in I second; FVC, forced vital capacity; ICS, inhaled corticosteroid; LABA, long-acting $\beta_{2}$ receptor agonist; LAMA, long-acting muscarinic receptor agonist; mMRC, modified Medical Research Council; OR, odds ratio; SGRQ, St George's Respiratory Questionnaire. 


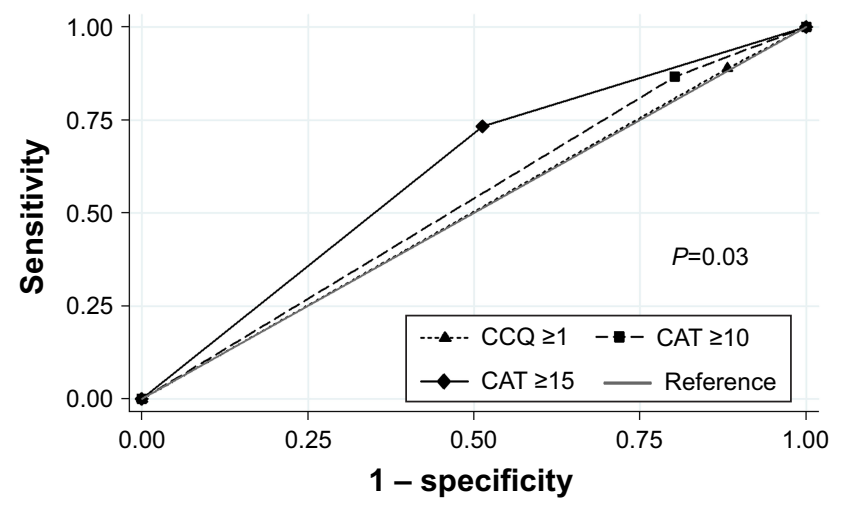

Figure 3 The receiver operating characteristic curve to compare the prediction of exacerbation according to the different cutoff levels of symptom assessment tools. Abbreviations: CAT, COPD Assessment Test; CCQ, Clinical COPD Questionnaire.

homogeneous questionnaires whose results correlate well, the mental domain of the CCQ exhibits a comparatively weak correlation with the CAT, which contrasts with the correlations observed between the CAT and the functional domain of the CCQ. ${ }^{33}$ The differences between the questionnaires themselves and the lack of additional analysis of each domain of the CCQ and subsequent consideration of psychological properties of patients might play a role in the superior predictive capacity of the CAT in our study. In addition, contrary to the CAT, there is no clinically defined threshold for "more symptomatic" in the CCQ, rather the makers of the assessment arbitrarily suggested using a range of scores from 1.0 to 1.5. This makes use of the CCQ difficult for both clinical practice and clinical research.

We found that a CAT score of $\geq 15$ is a leading risk factor for exacerbation event, even after adjustment for covariates. We previously suggested that the recommended CAT threshold for "more symptomatic" $(\geq 10)$ did not agree with the established mMRC threshold for discriminating "more breathlessness" ( $\geq 2)$; at the time, we suggested that a CAT score of $\geq 15$ may more reliably predict exacerbation events during the follow-up period. ${ }^{11}$ Similarly, Casanova et $\mathrm{al}^{10}$ proposed new thresholds for the CAT $(\geq 17)$ and the $\mathrm{CCQ}(>2.5)$ to predict all-cause mortality in COPD patients. We also used a CAT score of 17 and a CCQ score of 2.5 in our cohort, but the ability to predict the exacerbation was similar with values we suggested.

GOLD guidelines suggest using a CAT score of 10 as a threshold to distinguish COPD patients who are at higher risk of exacerbation and poorer self-perception of health status. Because a CAT score of 10 is equivalent to an SGRQ score of 25 , and a SGRQ score of $\geq 25$ is uncommon in healthy persons, a CAT score of $\geq 10$ is a highly acceptable and better threshold. Although we showed that a CAT score of $\geq 15$ may be a better predictor of exacerbation in COPD patients, we are not advocating for immediate changes in clinical guidelines. Importantly, we have shown a discrepancy in reference points used to indicate health status and those used to predict exacerbation. Our findings suggest that there is a clear need to consider which assessment tools are appropriate to use during evaluation of COPD patients; therefore, further studies are needed in this area.

There are several limitations of our study. First, the current observational cohorts enrolled COPD patients who were visiting the pulmonary department in a tertiary hospital, rather than enrolling those patients directly from their primary medical clinics. Thus, our cohort may not represent all COPD patients. Second, many patients did not carry out CCQ interviews which resulted in a high dropout rate. It could lead to bias. Third, we analyzed 1-year exacerbation without mortality as a primary outcome. To evaluate the impact of health status on mortality, the follow-up duration would have been short. However, because our cohort utilizes an ongoing prospective design, further studies can be performed.

\section{Conclusion}

Our results showed that CAT, a comprehensive and simple health status questionnaire, has better predictive capacity than CCQ on exacerbation. Furthermore, a CAT score of $\geq 15$ could be useful to classify COPD patients into higher risk of exacerbation or not. This suggests that new clinical threshold of CAT might be more useful to assess future risk of exacerbation in patients with COPD.

\section{Disclosure}

The authors report no conflicts of interest in this work.

\section{References}

1. Donaldson G, Seemungal T, Bhowmik A, Wedzicha J. Relationship between exacerbation frequency and lung function decline in chronic obstructive pulmonary disease. Thorax. 2002;57(10):847-852.

2. Bang KM, Gergen PJ, Kramer R, Cohen B. The effect of pulmonary impairment on all-cause mortality in a national cohort. Chest. 1993;103(2): $536-540$.

3. Cao Z, Ong KC, Eng P, Tan WC, Ng TP. Frequent hospital readmissions for acute exacerbation of COPD and their associated factors. Respirology. 2006;11(2):188-195.

4. Jones PW. Health status and the spiral of decline. COPD. 2009;6(1): 59-63.

5. Han MK, Muellerova H, Curran-Everett D, et al. GOLD 2011 disease severity classification in COPDGene: a prospective cohort study. Lancet Respir Med. 2013;1(1):43-50.

6. Vogelmeier CF, Criner GJ, Martinez FJ, et al. Global strategy for the diagnosis, management, and prevention of chronic obstructive lung disease 2017 report: GOLD executive summary. Am J Respir Crit Care Med. 2017;195(5):557-582. 
7. Miravitlles M, Ferrer M, Pont A, et al. Effect of exacerbations on quality of life in patients with chronic obstructive pulmonary disease: a 2 year follow up study. Thorax. 2004;59(5):387-395.

8. Soler-Cataluna J, Martínez-García MÁ, Sánchez PR, Salcedo E, Navarro M, Ochando R. Severe acute exacerbations and mortality in patients with chronic obstructive pulmonary disease. Thorax. 2005;60(11): 925-931.

9. Sullivan SD, Ramsey SD, Lee TA. The economic burden of COPD. Chest. 2000;117(2_suppl):5S-9S.

10. Casanova C, Marin JM, Martinez-Gonzalez C, et al. Differential effect of modified medical research council dyspnea, COPD assessment test, and clinical COPD questionnaire for symptoms evaluation within the new GOLD staging and mortality in COPD. Chest. 2015;148(1):159-168.

11. Lee C-H, Lee J, Park YS, et al. Chronic obstructive pulmonary disease (COPD) assessment test scores corresponding to modified Medical Research Council grades among COPD patients. Korean J Intern Med. 2015;30(5):629-637.

12. Pinto LM, Gupta N, Tan W, et al. Derivation of normative data for the COPD assessment test (CAT). Respir Res. 2014;15:68.

13. Nishimura K, Izumi T, Tsukino M, Oga T. Dyspnea is a better predictor of 5-year survival than airway obstruction in patients with COPD. Chest. 2002;121(5):1434-1440.

14. Domingo-Salvany A, Lamarca R, Ferrer M, et al. Health-related quality of life and mortality in male patients with chronic obstructive pulmonary disease. Am J Respir Crit Care Med. 2002;166(5):680-685.

15. Hurst JR, Vestbo J, Anzueto A, et al. Susceptibility to exacerbation in chronic obstructive pulmonary disease. $N$ Engl J Med. 2010;363(12): $1128-1138$.

16. Karloh M, Mayer AF, Maurici R, Pizzichini MM, Jones PW, Pizzichini E. The COPD assessment test: what do we know so far? A systematic review and meta-analysis about clinical outcomes prediction and classification of patients into GOLD stages. Chest. 2016;149(2):413-425.

17. Sundh J, Janson C, Lisspers K, Montgomery S, Stallberg B. Clinical COPD Questionnaire score (CCQ) and mortality. Int J Chron Obstruct Pulmon Dis. 2012;7:833-842.

18. Lung function testing: selection of reference values and interpretative strategies. American Thoracic Society. Am Rev Respir Dis. 1991;144(5): 1202-1218.

19. Wanger J, Clausen J, Coates A, et al. Standardisation of the measurement of lung volumes. Eur Respir J. 2005;26(3):511-522.

20. ATS statement: guidelines for the six-minute walk test. Am J Respir Crit Care Med. 2002;166(1):111-117.

21. Jones P, Harding G, Berry P, Wiklund I, Chen W, Leidy NK. Development and first validation of the COPD Assessment Test. Eur Respir J. 2009;34(3):648-654.

22. Kon SS, Canavan JL, Jones SE, et al. Minimum clinically important difference for the COPD Assessment Test: a prospective analysis. Lancet Respir Med. 2014;2(3):195-203.

23. Gupta N, Pinto LM, Morogan A, Bourbeau J. The COPD assessment test: a systematic review. Eur Respir J. 2014;44(4):873-884.
24. Hwang YI, Jung KS, Lim SY, Lee YS, Kwon NH. A validation study for the Korean version of chronic obstructive pulmonary disease assessment test (CAT). Tuberc Respir Dis. 2013;74(6):256-263.

25. Van der Molen T, Willemse BW, Schokker S, Ten Hacken NH, Postma DS, Juniper EF. Development, validity and responsiveness of the Clinical COPD Questionnaire. Health Qual Life Outcomes. 2003;1(1):13.

26. Kim SH, Oh YM, Jo MW. Health-related quality of life in chronic obstructive pulmonary disease patients in Korea. Health Qual Life Outcomes. 2014;12:57.

27. CCQ [homepage on the Internet]. CCQ Korean Version. Available from: http://ccq.nl/?wpsc-product=ccq-korean-korean-24h-version. Accessed November 18, 2017.

28. Kocks JW, Tuinenga MG, Uil SM, Van den Berg J, Ståhl E, Molen TD. Health status measurement in COPD: the minimal clinically important difference of the clinical COPD questionnaire. Respir Res. 2006; $7(1): 62$.

29. Jones PW, Quirk FH, Baveystock CM, Littlejohns P. A self-complete measure of health status for chronic airflow limitation. Am Rev Respir Dis. 1992;145(6):1321-1327.

30. Ferrer M, Alonso J, Prieto L, et al. Validity and reliability of the St George's Respiratory Questionnaire after adaptation to a different language and culture: the Spanish example. Eur Respir J. 1996;9(6): 1160-1166.

31. Jones P, Brusselle G, Dal Negro R, et al. Properties of the COPD assessment test in a cross-sectional European study. Eur Respir J. 2011;38(1): 29-35.

32. Ringbaek T, Martinez G, Lange P. A comparison of the assessment of quality of life with CAT, CCQ, and SGRQ in COPD patients participating in pulmonary rehabilitation. COPD. 2012;9(1):12-15.

33. Tsiligianni IG, van der Molen T, Moraitaki D, et al. Assessing health status in COPD. A head-to-head comparison between the COPD assessment test (CAT) and the clinical COPD questionnaire (CCQ). BMC Pulm Med. 2012;12:20.

34. Dodd JW, Hogg L, Nolan J, et al. The COPD assessment test (CAT): response to pulmonary rehabilitation. A multicentre, prospective study. Thorax. 2011;66(5):425-429.

35. Sundh J, Ställberg B, Lisspers K, Kämpe M, Janson C, Montgomery S Comparison of the COPD assessment test (CAT) and the clinical COPD questionnaire (CCQ) in a clinical population. COPD. 2016;13(1): 57-65.

36. Cave AJ, Atkinson L, Tsiligianni IG, Kaplan AG. Assessment of COPD wellness tools for use in primary care: an IPCRG initiative. Int J Chron Obstruct Pulmon Dis. 2012;7:447-456.

37. Briggs A, Spencer M, Wang H, Mannino D, Sin DD. Development and validation of a prognostic index for health outcomes in chronic obstructive pulmonary disease. Arch Intern Med. 2008;168(1):71-79.

38. Cleland JA, Lee AJ, Hall S. Associations of depression and anxiety with gender, age, health-related quality of life and symptoms in primary care COPD patients. Fam Pract. 2007;24(3):217-223.
International Journal of COPD

\section{Publish your work in this journal}

The International Journal of COPD is an international, peer-reviewed journal of therapeutics and pharmacology focusing on concise rapid reporting of clinical studies and reviews in COPD. Special focus is given to the pathophysiological processes underlying the disease, intervention programs, patient focused education, and self management protocols.

\section{Dovepress}

This journal is indexed on PubMed Central, MedLine and CAS. The manuscript management system is completely online and includes a very quick and fair peer-review system, which is all easy to use. Visit http://www.dovepress.com/testimonials.php to read real quotes from published authors. 